\title{
Slam Resistência: poesia, cidadania e insurgência
}

\author{
Slam Resistência: Poetry, Citizenship and Insurgence \\ Slam Resistência: poesía, ciudadanía y insurgencia
}

Daniela Silva de Freitas

\section{Resumo}

Este artigo investiga os entrelaçamentos entre poesia, cidadania e insurgência na São Paulo contemporânea a partir do Slam Resistência, uma batalha de poesia que acontece desde 2014, todos os meses, na Praça Roosevelt, no centro da cidade. Para tanto, dada a novidade que essa nova forma de poesia constitui, apresentaremos as origens e os percursos da slam poetry até sua chegada a São Paulo e discutiremos a forma como o slam transforma a relação entre público, poeta e poesia, redefinindo seus termos. Em seguida, veremos como, ao se afiliar simultaneamente aos suportes oral, visual e escrito, o slam mistura as esferas do público e do privado, do político e do pessoal. Dessa forma, no Slam Resistência, a prática da cidadania insurgente acontece no centro da pólis e toma a praça, ocupando e ressignificando o espaço público.

Palavras-chave: slam, poesia, cidadania.

\section{Abstract}

This article aims to investigate the interconnections between poetry, citizenship and insurgence in Slam Resistência, a poetry slam that, since 2014, occurs monthly in Praça Roosevelt, a square in the center of the city of São Paulo. The article starts by mapping the origins of slam poetry and its arrival in São Paulo. It also discusses the ways in which slam poetry transforms the relationship between public, poet and poetry, redefining these terms. We argue that, by mixing oral, visual and written elements, slam poetry blurs the limits between the public and the private, the personal and the political. In Slam Resistência, the practice of insurgent citizenship happens in the center of the polis, taking up the square, occupying and resignifying public space.

Keywords: slam, poetry, citizenship.

\section{Resumen}

Este artículo investiga los entrelazamientos entre poesía, ciudadanía y insurgencia en la São Paulo contemporánea a partir del Slam Resistência, una batalla de poesía que ocurre desde el año 2014, todos los meses en la Praça Roosevelt, en el centro de la ciudad. Dada la novedad que esta nueva forma de poesía constituye, empezaremos por presentar los orígenes y los recorridos de la slam poetry hasta su llegada a São Paulo y discutiremos la forma como el slam transforma la relación entre público, poeta y poesía, redefiniendo sus términos. Enseguida, veremos cómo, al afiliarse simultáneamente a los soportes oral, visual y escrito, el slam mezcla las esferas del público y de lo privado, de lo político y de lo personal. En Slam Resistência, la práctica de la ciudadanía insurgente ocurre en el centro de la pólis y toma la plaza, ocupando y resignificando el espacio público.

Palabras-clave: slam, poesía, ciudadanía.

Este artigo discute a relação do Slam Resistência com a questão da cidadania a partir da análise de edições do evento ocorridas entre os anos de 2016 e 2017. Junto com o rap, os saraus, as batalhas de MC's e, talvez, a literatura marginal, a slam poetry - ou simplesmente o "slam", que é como a maioria de seus participantes se refere tanto à poesia quanto ao evento -, especialmente em São Paulo, se configura, entre outras coisas, como mais uma manifestação da palavra cantada dentro do universo da cultura hip-hop e constitui uma das cenas culturais que mais crescem pelo país.

\footnotetext{
"Universidade Federal de Alfenas, Alfenas, MG, Brasil. (Dorcid.org/0000-0002-2670-3244. E-mail: danielasf@gmail.com
} 
Dada a novidade que essa nova forma de poesia constitui, antes de nos voltarmos para a análise dessa relação, apresentaremos suas origens e definições. Veremos como a slam poetry opera no interstício entre os suportes oral, escrito e visual e que, ao ocupar esse lugar, ela tensiona ainda mais os limites entre literatura e música, poesia e vida, arte e ativismo - limites já complicados por outras manifestações da cultura hip-hop. Ao longo desta investigação, perceberemos também que, como aponta Helen Gregory (2012), no caso da slam poetry, será particularmente relevante analisar não só o conteúdo dos poemas, mas também a forma em que esses poemas se realizam, seus contextos de produção e circuitos de divulgação e recepção. Além disso, veremos como a relação entre poesia e técnica no Slam Resistência constitui uma diferença significativa e fundamental no contexto de emergência de novos protagonismos culturais na cidade de São Paulo.

A slam poetry nasceu nos meados dos anos 1980, em Chicago. Herdeira da vasta tradição de poesia falada que já existia nos Estados Unidos - dos readings dos poetas beatniks; do spoken words de poetas negros, como Gil Scott-Heron, que já gravavam seus LPs bem antes da existência dos MC's; da poesia de Langston Hughes com suas emulações dos ritmos do jazz; e, segundo alguns críticos, do projeto de Walt Whitman de alcançar o grande público através da poesia - e influenciada pelo surgimento da performance art dos anos 1960, a slam poetry (em alguns lugares dos Estados Unidos, especialmente em Nova Iorque) associou-se à cultura hip-hop e, como prática cultural diaspórica, espalhou-se pelo mundo. Hoje há slams de poesia na França, no Reino Unido, na Alemanha, no Canadá, na Austrália, no Zimbabwe, em Madagascar, em Cingapura, no Japão etc. Representantes de diferentes países participam da Copa do Mundo de Slam em Paris.

O poetry slam é uma batalha de poesia falada, cujas cinco regras principais, apesar de variarem de lugar para lugar, tendem a permanecer relativamente as mesmas: os competidores têm três minutos para apresentar sua poesia autoral e inédita naquele slam, sem o auxílio de adereços de cena ou acompanhamento musical. As poesias são julgadas pelo público e pelos jurados imediatamente após sua leitura/recitação/acontecimento, em uma escala de zero a dez. O júri é constituído por pessoas escolhidas aleatoriamente na plateia. Das notas dos cinco jurados, a maior e a menor são descartadas, compondo uma nota final que varia entre zero e trinta pontos. O poeta geralmente passa por três rodadas, tendo que apresentar três poesias vencedoras antes de se tornar o campeão da noite.

Marc Smith, fundador do primeiro slam do mundo, era trabalhador da construção civil e poeta nos meados dos anos 1980. Smith diz que chegou no formato do slam gradualmente, tentando transformar os eventos de leitura de poesia organizados por ele e seus amigos em bares de um bairro operário de Chicago em uma espécie de show que atraísse aqueles que não se viam acolhidos pelo ambiente das leituras de poesia tradicionais. Desde 1986 até hoje, o Uptown Poetry Slam acontece toda semana no Green Mill. Apesar de Smith se declarar e ser reconhecido como criador do formato, nenhuma taxa precisa ser paga pela utilização do nome ou do método: as regras estão disponíveis no site de Smith e ele estimula que elas sejam adaptadas por cada slam, de acordo com a realidade local. Hoje em dia, por exemplo, o próprio Uptown Poetry Slam conta com a presença de uma banda de jazz, que improvisa um fundo musical que tenta combinar e complementar o tom dos poemas apresentados ao longo da noite. No Brasil, é comum que, durante o evento do slam, haja a participação de artistas convidados, que lançam livros ou CDs, falam sobre seu trabalho, lêem suas poesias - que não concorrem na batalha - ou apresentam pocket-shows.

Em The cultural politics of slam poetry, Susan Somers-Willet comenta sobre algumas implicações políticas das regras do slam, que se constituem em contraste com o modelo de poesia tradicional:

Além de alimentar uma atmosfera contracultural e de disseminar a poesia em lugares nãoconvencionais, o slam se desenvolveu através do exercício de certos ideais democráticos em contraste a convenções acadêmicas exclusivistas. [...] Desde o começo, o poetry slam adotou uma política de portas abertas: qualquer um pode se inscrever para batalhar, e qualquer um no público está qualificado para julgar. [...] Tal ênfase no público como crítico se distingue dos eventos de leitura de poesia mais tradicionais, que celebram ou reverenciam autores 
previamente classificados como dignos de valor por autoridades literárias. O poetry slam foi fundado sobre as premissas de que o poeta deve convencer o público a ouvi-lo, que qualquer um pode julgar uma competição e que a competição deve ser aberta a todas as pessoas e todas as formas de poesia. Slam poetry é verso que, pelo menos em teoria, pode ser acessado por qualquer um e cujo valor qualquer um pode determinar. A acessibilidade da slam poetry é facilitada e talvez exigida pela linguagem da performance, que se submete ao tempo e o espaço, e - talvez mais importante - à atenção da plateia. Em competições de slam nacionalmente certificadas, os poetas têm uma janela de no máximo três minutos, que, como o poeta e showman Bob Holman aponta, é exatamente a duração de uma canção popular (Somers-Willet, 2009, p. 5-6, tradução nossa).

Na slam poetry, a poesia deixa o ambiente acadêmico, abandona os circuitos tradicionais de curadoria e produção de sentido, flerta com a canção popular e torna-se uma prática coletiva e, como tal, se estabelece no limite entre o oral, o escrito e o visual, fazendo da performance um elemento central. $\mathrm{O}$ significado dos poemas se constitui tanto através da narrativa em primeira pessoa sobre a experiência do/a slammer (narrativa que ele/a escreve e, desejavelmente, memoriza antes do evento, raramente improvisa como nas batalhas de MC`s), da voz e do corpo do/a poeta, quanto da relação com a voz, o corpo e as histórias do público que ouve. "Em vez da experiência da poesia ser sobre o privado" (a relação entre autor e público que comumente se estabelece ao lermos poesia no papel), “a slam poetry encena um potencial dialógico [...] entre autor e público. [...] Nesse sentido, o slam se assemelha ao movimento feminista dos anos 1960 e 70, que proclamava que o pessoal é político" (Somers-Willet, 2001, p. 43-44, tradução nossa). Maria Damon fala sobre como "[o] slam oferece um meio importante para uma atividade poética de raiz que reescreve a cena lírica privada em um veículo para o discurso público" (Damon, 1998, p. 326, tradução nossa). Para Hellen Gregory (2008; 2012), a slam poetry é um “for[u]m”, já que ao mesmo tempo em que é uma forma específica de poesia, ela constitui um fórum, um evento em um espaço público, onde histórias e identidades sociais são negociadas. Somers-Willet, Damon e Gregory mostram como, nos Estados Unidos e no Reino Unido, o slam constitui-se em uma linguagem que se caracteriza por operar no limite entre privado/público, pessoal/coletivo, transformando a relação que, desde a popularização da imprensa, rege a interação entre público/leitor, poeta e poesia. Em seguida, veremos como essa questão é ainda mais complexa na forma em que a slam poetry se manifesta hoje em São Paulo.

O primeiro slam de poesia no Brasil foi o ZAP! Slam (ZAP é uma abreviação para Zona Autônoma da Palavra), organizado por Roberta Estrela D'Alva desde 2008 no Núcleo Bartolomeu de Depoimentos, no bairro de Pompeia, em São Paulo. Roberta é tanto uma das principais poetas, como uma das mais antigas pesquisadoras da cena no Brasil. Além de ser responsável pela organização do primeiro evento de slam poetry no país, ela foi a primeira slammer brasileira a participar da Copa do Mundo de Slam, em 2011, e a primeira pesquisadora a publicar um artigo sobre a cena da slam poetry em São Paulo. Seu documentário Slam: voz de levante (2018), dirigido em parceria com Tatiana Lohmann, foi lançado no Festival do Rio em 2017 e ganhou o prêmio de melhor direção de documentário e prêmio especial do júri.

O segundo slam a ser organizado na cidade de São Paulo foi o Slam da Guilhermina, que acontece desde fevereiro de 2012 ao lado da estação de metrô Guilhermina-Esperança, na Zona Leste de São Paulo, ao redor de um lampião. O espaço de realização dos slams brasileiros constitui uma diferença significativa com relação à versão americana: nos Estados Unidos, as batalhas ocorrem sempre dentro de espaços fechados - teatros, bares ou casas de show -, onde é necessário comprar ingresso para participar do evento. No Brasil, mesmo nas ocasiões em que ocorrem em espaços fechados, os slams costumam ser sempre gratuitos. Muitos slams, como o da Guilhermina e o Resistência, são realizados em praça pública, o que amplia ainda mais a sua capacidade enquanto fórum.

Criado a partir do modelo do Slam da Guilhermina, segundo seus organizadores, o Slam Resistência é o oitavo slam mais antigo da cidade (ao final de 2017, estimava-se que houvesse cerca de quarenta e quatro slams só em São Paulo), fruto das intervenções poéticas feitas nas "Quintas de Resistência" - encontros que aconteciam na Praça Roosevelt, no centro de São 
Paulo, entre os Advogados Ativistas e os movimentos sociais para discutir a truculência da polícia durante as manifestações de 2013.

Desde outubro de 2014, todas as primeiras segundas-feiras do mês, o slam ocupa a praça. Seu público e seus poetas são majoritariamente jovens que têm entre catorze e trinta e cinco anos. Devido à sua localização, o Slam Resistência congrega pessoas vindas de diferentes áreas da cidade, que seguram a respiração a cada poema declamado sem microfone, no meio da praça barulhenta. No ano de 2017, o público de cada edição variou entre cem e trezentas pessoas audiência que se amplia ainda mais através da página do slam no Facebook, que tem mais de meio milhão de seguidores.

Acreditando no que dizia Paulo Leminski sobre o futuro da poesia ser visual, desde o começo, os organizadores do slam têm parceiros que gravam alguns dos poemas recitados toda noite em vídeos, que eles disponibilizam na sua página do Facebook após o evento. Além dos vídeos dos poemas, eles também publicam notícias, reportagens, imagens e vídeos que, segundo eles, apresentam conteúdo que se alinha com o objetivo de resistência do slam. Toda essa movimentação virtual, eles acreditam, amplifica e suplementa o que acontece na praça. ${ }^{1}$

Nesse ponto, há uma distinção central entre o que geralmente é dito sobre a impossibilidade de mediação da experiência da performance e a prática performativa do Slam Resistência. Específica ao seu espaço e tempo, tal como pesquisadores como Paul Zumthor (2014) afirmam, a performance não pode ser capturada através de gravações em vídeo e áudio: ela só pode ser completamente acessada em presença, no momento do seu acontecimento, através de seus cheiros, barulhos, energias e presenças de outros corpos e emoções coletivas, jamais em virtualidade. No artigo "Um microfone na mão e uma ideia na cabeça - o poetry slam entra em cena", Roberta Estrela D'Alva afirma que:

De fato, a "aura" (Benjamin, 1985) do slam, o momento presente em que o encontro se dá, não é possível de reprodução, e muito embora existam registros dos campeonatos e até mesmo livros de antologias com os poemas que são recitados, nada substitui a presença física, o encontro, o diálogo entre as diferenças, ponto central desse tipo de manifestação (D’Alva, 2011, p. 121).

Enquanto performance, os textos apresentados no Slam Resistência só se realizam na interação entre artista e público, mas, nesse caso, há pelo menos duas esferas de recepção/produção dessa poesia: a praça e a página (virtual). Através dos vídeos das poesias, compartilhados na página do slam no Facebook, seus mais de 500.000 seguidores podem participar - curtir, comentar e compartilhar -, ainda que em virtualidade, da experiência da performance, que reverbera em compartilhamentos pela rede, alcançando um público ainda maior, estendendo o diálogo para além da praça. Dessa maneira, ao mesmo tempo em que a experiência da performance da praça nunca será a mesma daquela capturada em vídeo, a interação online constitui parte importante do processo de construção de significado dessas poesias.

Como no caso americano (e no caso do rap), no Slam Resistência, as performances do/as poetas tendem a ser narrativas em primeira pessoa que tematizam sua experiência de vida, traço que Roberta Estrela D'Alva (2011) chama de "autorrepresentação". Ao relatar casos vividos por ele/as, os/as poetas expõem a lógica do funcionamento dos mecanismos de controle biopolítico e enunciam os limites da democracia dentro da sociedade brasileira cordial. São temas como a desigualdade, a exclusão, o machismo, o racismo e a homofobia - além de certo flow de rap e de seus três minutos de canção, como aponta Somers-Willet (2009) sobre a slam poetry americana - que garantem o sucesso da poesia entre júri e plateia.

Na edição especial de julho de 2017, por exemplo, Paulina Turra fez uma poesia sobre a descoberta da sua sexualidade e os problemas que teve em conversar sobre o assunto com sua família e amigos:

\footnotetext{
${ }^{1}$ Contudo, como geralmente acontece na cultura hip-hop, a divulgação desses vídeos por parte do Slam Resistência é ambígua e é motivo de polêmica entre poetas, principalmente poetas profissionais, que acreditam que os organizadores deste slam se apropriam das poesias e usam os vídeos em benefício próprio, obtendo verbas e editais que não chegam aos/às poetas.
} 
Agora eu tenho 19 anos, mas parece que eu só tenho 3 porque foi só com 15 anos que eu me assumi gay.

Gay não, sou sapatão,

tem gente que me olha e faz essa confusão.

Hoje em dia eu nem ligo, mas antes não era assim.

Já tive que me disfarçar, fantasiar

para esconder essa pessoa dentro de mim

tenho até foto indo pra festa,

salto alto, meia-calça,

vestido tubinho com as costas abertas,

rímel, lápis, sombra,

cabelo mais alisado e californiana nas pontas.

Quem me conhece hoje em dia

olha a foto, dá risada e zomba,

mas aquela era a minha armadura,

porque ser como eu queria me dava vergonha.

Falar com a minha mãe? "Shhhi, fala baixo, nem sonha",

falar com o meu pai? "Shhhi, fala baixo, nem sonha",

falar com a minha amiga? "Ih, vai que ela estranha".

Então um dia me tranquei no banheiro com a minha avó,

finalmente da minha garganta ia tirar aquele nó,

falei que queria ser menino, achava que ia ser melhor,

Ela falou pra eu não contar pra ninguém,

que se eu contasse ia ser pior

Depois disso até consegui namorado,

por essa boca vários pintos ja passaram,

eu até que gostava, eles adoravam,

queria saber se eu já fosse assim se eles teriam se interessado.

Hoje em dia eu nem ligo, sou do jeito que eu quiser,

o jeito que eu falo, que eu penso, que eu me movo,

é meu jeito de ser mulher!

E vai ter gente falando que eu tô confusa,

mas confuso é quem quer me dar beijo,

mas não beija porque se assusta.

Eu beijo mina, bicha, diva, viada e sapatão.

Eu não tenho lista de pré requisitos.

Eu não tô atrás de um padrão.

E se hétero quiser ficar comigo na balada,

não é porque tá bêbado e a visão tá embaçada,

é porque eu sou uma puta mina gata

e de macho eu não tenho nada.

Eu posso até ter falado muito,

me embolado e falado demais,

mas é que eu só comecei a falar

três anos atrás (Slam Resistência, 2017a).

A poesia rendeu muitos "ou" durante sua execução e um coro de "tchum-tcha/tcha-tchumtchum-tcha" ao final - gritos que simbolizam a aprovação do poema por parte do público desse slam. Por vezes, os gritos de "ou" foram tão fortes e longos que interromperam a apresentação da poeta. Paulina, sempre confiante - sem vacilar, gaguejar ou diminuir o tom de voz -, tinha que retomar os versos anteriores para poder prosseguir. Na página do Slam Resistência no Facebook, o vídeo tem mais de 700 mil visualizações, quase 15 mil compartilhamentos e 4 mil comentários.

Transcrita para a página, a poesia de Turra, como todas as poesias que analisaremos aqui, perde um pouco de sua potência, chega a parecer simplista. Como afirmamos no começo do texto, a poesia do slam - como a do rap, argumenta Irmani Perry (2004) - acontece na interface da escrita, do visual e do oral. Ela é escrita pelo poeta e desejavelmente memorizada, mas é feita 
para ser ouvida e imediatamente compreendida após sua primeira execução. Sendo assim, diferentemente de certa poesia tradicional, a simplicidade dos versos, o emprego de vocabulário corrente, a construção de frases em forma direta e até a repetição enfática de certas palavras, trechos ou ideias tornam-se recursos desejáveis. Voz, entonação, ritmo, flow, olhar, jeito de corpo e gestos são componentes essenciais na experiência da oralidade e da performance, não acessórios, o que precariza o entendimento da poesia quando usamos exclusivamente a palavra escrita como suporte de leitura.

O assunto do poema de Paulina é, a princípio, um drama privado. Ele é exposto em uma narrativa que torna essa privacidade ainda mais evidente: seus personagens são sua avó, sua mãe, seu pai, suas amigas; a linguagem usada se assemelha com a de um diário, em tom de confidência, com a fotografia solta entre as páginas. Contudo, o interlocutor de Paulina é a praça. É ao público que ela pede desculpas por ter falado demais. É ao fórum do slam que ela anuncia finalmente ter encontrado sua voz. O drama privado de Paulina é ovacionado por todos. Só ela pode falar como se sente, só ela tem autoridade para narrar sua experiência, mas sua voz é acolhida na ágora, sua luta diz respeito a todos. Como no lema feminista, a vida pessoal de Paulina é política, o privado se torna questão pública.

O tom íntimo da poesia de Turra contrasta com a visão macropolítica de Tawane Theodoro, cuja performance na edição de março de 2017 é o vídeo mais assistido da página do slam no Facebook: tem quase 8 milhões de visualizações, 20 mil comentários e mais de 200 mil compartilhamentos. Os trechos abaixo foram retirados da transcrição do poema completo, postado pela própria Tawane nos comentários de seu vídeo no Facebook do Slam Resistência:

Eu não queria ser feminista

Eu não deveria ser feminista

Em pleno século XXI minha gente, feminismo não deveria nem existir...

Calma sociedade, não comece a sorrir

É pq mulheres não tinham que precisar resistir tanto assim

\section{$[\ldots]$}

Percebemos que quando estamos na rua, a noite, e observamos um cara se aproximar

Já começamos a acelerar

O coração, disparar

Começamos a rezar

"Que seja só um assalto, e que só levem o meu celular"

Acha que ainda assim é mimimi

Conversa fiada?

Como já escutei muitas vezes...

Falta de vergonha na cara?

Vamo ser mais didática então

Vamo jogar estatística

Já que o óbvio parece que saiu de questão

O Brasil é o $5^{\circ}$ pais mais violento para mulheres do mundo

Cada dia o feminicidio aumenta

E com a mulher preta a estatística é ainda mais violenta.

Homicídio de mulheres negras aumentou 54\% em 10 anos

A cada 11 minutos uma mulher é estuprada,

$70 \%$ dos casos de estupro a vítima era próxima do agressores

Em média 47,6 mil mulheres são estupradas por ano, sendo que nem $30 \%$ delas denunciam 3 em cada 5 mulheres vão sofrer algum tipo de violência em algum relacionamento Até 2030 podem morrer 500 mil mulheres vítimas de violência doméstica no mundo $94 \%$ das mulheres já foram assediadas verbalmente e $77 \%$ ja foram assediadas fisicamente 
E acha que o feminismo é exagero?

O feminismo já é o desespero

Pq estamos em uma sociedade que eu ainda tenho que explicar

Que somos seres humanos e não algo que possa se descartar.

Então não venha me pedir delicadeza

Pois tenha certeza

Que aqui...Isso não vai rolar

Foi-se a época de gentileza

Vamo chegar com dois pé no peito memo

Passar por cima de qualquer tipo de sujeito

Derrubando esse seu preconceito

[...]

Mulheres precisam ser feministas...

Mas tomara que em algum dia

não precisem mais ser

E que finalmente alcancem o seu devido poder

E eu peço pra qualquer Deus de qualquer religião

Que a próxima geração

Não enfrente um mundo tão sem noção (Slam Resistência, 2017b).

Tawane Theodoro fala sobre o feminismo em tom argumentativo, explicando àqueles que acham que feminismo é "mimimi" a necessidade de sua existência. Para isso, ela recorre a fatos concretos, usando tanto a sua própria experiência e a experiência de mulheres ao seu redor quanto números e estatísticas oficiais para mostrar - didaticamente, como ela mesma diz como o machismo ameaça diariamente a vida de todas as mulheres. Perto do final, a poeta adota uma linguagem belicosa e o propósito pedagógico e mobilizador do poema de Tawane se torna ainda mais evidente.

Nos comentários do vídeo na página do Slam Resistência, o engajamento do público é forte: há um comentário dos organizadores do slam, chamando a atenção de Tawane para o alcance de sua poesia; há um comentário de Tawane, agradecendo ao público, e outro com a transcrição de sua poesia; seu pai comenta sobre o orgulho que tem da filha; meninas falam sobre como se sentem representadas por Tawane, seja através da reprodução de um trecho da letra, seja através da narrativa de suas histórias pessoais; alguns homens criticam o assunto da poesia e a atitude de Tawane e recebem centenas de respostas, muitas com opiniões contrárias às deles. Mesmo tendo sido publicado em 22 de março de 2017, o comentário mais recente no vídeo tinha sido postado meia hora antes da redação deste parágrafo, em fevereiro de 2018.

Patrícia Meira também discute gênero, raça e violência no poema que ela apresentou na edição de novembro de 2016:

Começo sem me desculpar ou pedir licença

Nascer mulher virou uma sentença

E meu corpo está demasiadamente cansado

de ser chicoteado pelos padrões impostos

pela mão nojenta do patriarcado

A mulher que dizem ter saído do lado

parece mais ter sido...

moldada pra ficar debaixo dos pés

Escarraram na minha vida

estupraram a minha história

da senzala à casa grande,

os abusos não são de agora

Pelo contrário

Há anos a mulher sofre abusos diários

Carrega no corpo um fardo 
pois o jugo de ter uma ...buceta

fica ainda mais pesado

Então não me peçam pra ser mais maleável

se vocês não sabem o que é

ter os sonhos roubados

o destino violado

e ter que andar com os ombros calejados

por ter que carregar o peso de um fardo

que não era meu

Eu sei o que é andar com medo

Você não vê, mas eu vejo

o pavor no rosto de uma mulher quando não está acompanhada

que precisa... da presença máscula de um homem pra ser mais respeitada

pelo menos na rua, já que não é em casa

Então fala,

Diz pra mim que você sabe o que é sangrar

e eu nem to falando de menstruar

Diz pra mim que você também tomba um pouco

quando vê o corpo de uma mulher tombar

e não é do jeito que ensinou a Karol Conka

é morto mesmo

Eu sei o que é andar desprotegida

Afinal, qual é a Maria que oferece proteção

e as mulheres clamam?

Porque a porra da Maria da Penha

em nada protege as Marias que apanham

Se necessário for, eu vou gritar

Quem sabe assim a minha voz se faz escutar

Porque eu sei como é

ser negra, nordestina e fora do padrão

Eu sei como é

ser preta, periférica, homossexual e ser mulher

Você não sabe

mas eu sei como é!

[Valeu!] (Slam Resistência, 2016a).

Como mulher, lésbica, negra e periférica, Patrícia reflete sobre o jugo do patriarcado e do colonialismo sobre sua vida. Novamente, seu lugar de fala lhe confere autoridade para levantar esse debate na ágora, tanto que ela não precisa pedir licença ou desculpas para tomar a palavra e, ainda assim, ser ouvida e aplaudida por todos. Em seu artigo, Roberta Estrela D'Alva fala sobre como o slam se configura como "um espaço autônomo onde é celebrada a palavra, a fala, e, ainda mais fundamental num mundo como o que vivemos - a escuta" (D'Alva, 2011, p. 125).

Em "Slam poetry: ambivalence, gender, and black authenticity in 'slam"', Susan Somers-Willet (2001) afirma que, enquanto os poetas mais bem-sucedidos no mundo do slam americano são homens negros, o público dos slams é majoritariamente composto por casais heterossexuais brancos. Essa relação entre autor e plateia, ela argumenta, alimenta um certo fetichismo ambivalente, como conceituado por Homi Bhabha, consequência da elisão que ocorre entre o performer e sua identidade performativa e do valor dado à autenticidade que a experiência da negritude agrega à poesia. No Brasil, apesar do slam também ter se tornado uma "arte de autoproclamação" - "a identidade que se torna declaração política através da poesia", nas palavras de Somers-Willet (2001, p. 44) - e da encenação dessa identidade passar quase que necessariamente por um essencialismo estratégico, como diria Gayatri Spivak (1987), existem algumas diferenças fundamentais nesse circuito de produção e recepção do slam.

Talvez por contraste com as batalhas de MC's e seu universo majoritariamente masculino, o protagonismo da slam poetry no Brasil tende a ser feminino: Roberta Estrela D'Alva, Mel Duarte, Luz Ribeiro, Mariana Félix, Luíza Romão, Kimani, MC Martina, Carol Dall Farra, Gênesis, Pieta Poeta, 
Meimei Bastos e Luna Vitrolira - além de Paulina Turra, Tawane Theodoro e Patrícia Meira - são apenas alguns dos nomes que podemos citar. ${ }^{2}$ Muitas dessas poetas têm livros publicados (impressos ou audiobooks) e outros projetos de poesia além do slam. Porém, o slam não se faz a partir de nomes famosos, argumenta Roberta Estrela D'Alva, o slam é uma comunidade:

O termo "comunidade" define bem os grupos que "praticam" o poetry slam, já que esses vêm se organizando coletivamente em torno de um interesse comum, sob um conjunto mínimo de normas e regras. As comunidades cultivam o respeito aos fundadores do movimento e conhecimento detalhado sobre sua recente história, seus fundamentos e "filosofias". Ainda dentro dessa vocação comunitária, muito embora existam "figuras carimbadas" e habitués que frequentam regularmente os slams, tornando-se uma espécie de "personagens", não há incentivo à criação de poetas "super-stars", mas pelo contrário, prega-se que o propósito do poetry slam não é a glorificação do poeta em detrimento de outros, mas a celebração da comunidade à qual ele pertence (D'Alva, 2011, p. 121).

Dentro dos slams brasileiros, como nas batalhas de MC's (Teperman, 2011), há alguns participantes que se tornam rappers ou poetas profissionais, mas esses representam um número pequeno do conjunto dos competidores. Além disso, o público dos slams é formado por jovens que parecem bastante interessados/as na interface entre arte e ativismo típica dessa forma de poesia. Sendo assim, a centralidade dos temas identitários nos slams brasileiros parece se conectar a outros fatores. O principal deles parece ser a luta por direitos.

Lucas Koka Penteado (antes de se tornar ator de Malhação: viva a diferença) era estudante secundarista, líder da ocupação na sua escola, a Escola Estadual Caetano de Campos, que fica em frente à Praça Roosevelt, onde o Slam Resistência acontece. O poema que ele apresentou no slam foi um dos primeiros a viralizar na internet, em dezembro de 2016. No poema, Lucas conta sobre sua vida e sua luta por educação:

Boa noite "pa" geral

Era uma vez...

Não! Pára! Que isso aqui não é conto de fada!

E a história que vai ser relatada é só realidade

Conta as memórias de uma vida pacata

que esmagou a maldade

1996, quatro horas da manhã

dilatação de quatro dedos

mas não tinha parteiros

A saúde onde eu moro

me dá nos nervos.

Nome da mãe?

Andréia

Preta

Nesse mundo é treta

Quando madura

via que a vida era dura

Parecia que Deus olhava e dizia

- Poucas "ideia"

Prazer! Sou sim o desgraçado

como o engravatado tinha me falado

É, mas ele ficou impressionado

porque além de negro drama, sou negro estudado

[ou!]

\footnotetext{
${ }^{2}$ São tantas as poetas e os poemas que, inspiradas no Slam das Minas DF, as poetas Mel Duarte e Luz Ribeiro, junto com Pam Araújo e Carol Peixoto, fundaram o Slam das Minas SP, do qual só mulheres podem participar como poetas, júri ou organização. O propósito do Slam das Minas, segundo as organizadoras afirmam em seu site, é "criar um espaço de voz e acolhimento para as minas, monas e manas além de garantir uma vaga feminina para o Slam BR”. Em 2019, além de São Paulo e Brasília, há slams exclusivamente femininos em cidades como Rio de Janeiro, Porto Alegre, Salvador, Recife e Belém.
} 
E eu sei

[ou! Caralho!]

E eu sei que tenho muito a estudar,

Porém na academia da hipocrisia

a matéria que eu não entendia eles querem tirar

[ou!]

Mas um dia

um dia eu chego na universidade

Eles nem tão ligado que a vida serviu de faculdade

Tinha apenas três matérias: miséria, escravatura e infelicidade

Pois é, Brasil, eu nunca tive um "boot" de mil

mas no sistema eu vou tentar dar uma bota

porque eu quero ver, meu bem,

quando no ENEM eu tirar 100

eles falarem que foi cota.

[ou! Tchum-tcha tcha-tchum tchum-tcha! Tchum-tcha tcha-tchum tchum-tcha!] (Slam Resistência, 2016b).

Nela, Lucas relê e atualiza o "Negro drama", do Racionais MC's (2002). Ele começa a narrativa, como Mano Brown, contando a história de seu nascimento. Sua mãe e ele não tiveram uma vida fácil, mas o caderno desse pretinho não é um fuzil, como diz a letra do rap. Lucas se formou na escola do negro drama, aprendeu com a miséria, a infelicidade e as heranças da escravatura, mas, além de negro drama, ele também se tornou um negro estudado. Foi a história real da vida de Lucas - como a do drama de Brown - que lhe rendeu o primeiro lugar no slam naquela noite de segunda.

Devido ao seu interesse em estar "na sintonia dos protestos, dos movimentos sociais e do enfrentamento político ativo", de se configurar "para além das poesias", como fórum de discussão de "formas de Intervenções socio-culturais no meio da babylônia de concreto", conforme o Slam Resistência se descreve em sua página no Facebook, os organizadores participaram da ocupação da Escola Estadual Caetano de Campos e promoveram uma edição do slam dentro da ocupação. Foi depois desse slam que Koka, que já era frequentador, apresentou sua poesia no slam na praça, onde ele foi apresentado pelo slammaster como o terror de Geraldo Alckmin, governador de São Paulo na época.

Dentre alguns dos poemas apresentados em 2016 que versam diretamente sobre o cenário político atual estão os de Daniel Gtr, comparando o contexto e certos personagens da política brasileira atual à Alemanha de Hitler, e o de Lucas Afonso, representante do Brasil na Copa da França de 2015, sobre o golpe, a PEC do congelamento dos gastos públicos por trinta anos e a ditadura. O vídeo do poema de Gtr foi tirado do ar na página do Slam Resistência no Facebook repetidas vezes, devido a denúncias de conteúdo impróprio. Hoje, na página, só podemos ver aquele que Daniel chama de "Parte II" (Slam Resistência, 2016c). Nele, Daniel fala contra a bancada evangélica, contra a mistura entre política e religião e sobre a natureza revolucionária de Jesus Cristo - um tema bem complicado para muitos evangélicos. O poema de Lucas Afonso segue transcrito:

Não que eu não peque, mas essa PEC tá tirando a favela

Mais um gol contra, que muita gente comemorou

É cada $7 x 1$ que cai na conta do trabalhador

A mão que bateu panela não é a mão que lava a panela

Foi pra janela cantar o hino de camisa amarela?

E amarela e morre de medo de encontrar

Favela na lista de aprovados no vestibular

Imagina a tortura pra quem apoiou a ditadura

Encontrar a filha da empregada de beca na formatura

Aí não atura, mas tenha calma patrão, não dá na vista, mas seu filhão se formou, pedindo cola pra cotista 
Parece até piada do Sensacionalista

O filho de chefe põe no Face que vagabundo é artista, bolsista, cotista

Mais um gol contra. Faltou passar na tela um informe:

de que time era a camisa debaixo do uniforme do juiz

que foi conivente e pouco diz sobre o golpe que a democracia tomou no nariz

com tudo transmitido em rede nacional, com o apoio da TV, do rádio, da revista, do jornal

Foi cinematográfico, até escuta ilegal

Um abraço pra quem botou fé no japonês da federal!

Fica esperto com dengue, zika, chikungunya

Mas de olho aberto com Temer, Aécio, Eduardo Cunha

São livros de alto calibre que a quebrada impunha

E acredite: golpista a gente arranca na unha

Terceiro turno, cês não passaram nas urnas, aliás não conseguiram

explicar lista de Furnas

Quem levantou castelos, quem acumulou fortunas

A história dessa terra ainda tá cheia de lacuna

Vai vendo, certo dia, estive em uma manifestação

Tomei um soco na cara no meio da confusão

No outro dia, jornal, me vi na televisão:

policial agredido com cabeçada na mão

Os fins não justificam os meios de comunicação

Se a versão de quem oprime vira nossa opinião,

é fácil confundir quem bate com que te estende a mão

Se te oferecem o céu, te empurrando pro chão

Não vai fazer gol contra e sair comemorando, pelo amor

até torturador tão homenageando

2 mil e pouco, o certo sai pelos cano, opressor tem medo de ver

o oprimido levantando e batendo no peito gritando

"é noix": nosso povo sagaz, desespero pra algoz

Mas eles venceram, sinal fechado pra nós

Ainda vivemos como nossos pais, ou nossos avós

Exalto a voz, solto meu verso na rua,

correndo o risco do após, sozinho em noite sem lua

Sei que a maldade é veloz, o mal também não recua

Mas não estamos a sós

A LUTA CONTINUA! (Slam Resistência, 2016d).

Nesse poema, Afonso organiza acontecimentos e personagens da política recente - a proposta de emenda à Constituição que congelou os gastos públicos, inclusive os investimentos em saúde e educação, pelo período de trinta anos; o golpe que tirou a presidente do poder, as manifestações de 2013, a ditadura; os paneleiros, os cotistas, os torturadores, os artistas, os manifestantes, a polícia, os políticos, a mídia golpista - em uma mesma narrativa. $\mathrm{O}$ tom do poema de Lucas é propositivo, como o de Tawane Theodoro, mas o didatismo é parcialmente substituído pela ironia da comparação desses acontecimentos com a derrota sofrida pela seleção brasileira de futebol na final da Copa do Mundo do Rio, de 2014 - o humilhante 7 a 1 que se tornou meme na internet, símbolo das muitas derrotas trazidas pelos megaeventos, contra os quais tantos manifestantes protestaram.

O poema de Lucas termina chamando todos para a luta, porque apesar de o sinal estar fechado para nós e ainda sermos como os nossos pais, como dizia a canção contra a ditadura, o potencial do cenário de hoje é outro: a quebrada hoje empunha ameaçadores "livros de alto calibre". Mesmo que isso signifique pôr suas vidas em risco, ele, como os outros poetas e frequentadores do slam, ocupam a praça com seus versos. E essa nova articulação política e cultural faz toda a diferença. 
Na edição de março de 2017 do Slam Resistência, a primeira daquele ano, o/as participantes foram coagidos pela polícia a se dispersarem e cancelarem o evento. $\mathrm{O}$ momento foi gravado e pode ser assistido na página do Slam no Facebook (Slam Resistência, 2017c). Com a lei do artista de rua nas mãos, os organizadores tentavam argumentar para que o direito de recitar poesia em praça pública fosse respeitado. O ocorrido se alinha com as decisões da gestão do prefeito João Dória, como a de cobrir de cinza os muros de grafite que se espalhavam pela cidade de São Paulo, conforme aponta o poeta Daniel Gtr no vídeo. Desde então, a cada edição daquele ano, o slam sofreu constantes ameaças da Guarda Municipal. Em dezembro do mesmo ano, a final anual do evento, que seleciona, dentre os/as ganhadores de cada edição mensal, o/a poeta que vai para a final estadual, teve que ser simplificada e encurtada por conta do assédio dos policiais. Em março, os policiais disseram que, se os organizadores não encerrassem o evento, a Tropa de Choque viria com suas bombas para dispersar todo o público, conforme documentado no vídeo. Os organizadores temem que qualquer ação mais violenta seja tomada por parte da polícia, principalmente por conta da idade dos frequentadores do evento, do risco que as ações da polícia podem representar para as vidas daqueles jovens.

Dentro desse contexto, podemos perceber, então, que além da luta por direitos ser tema e preocupação de grande parte dos poemas apresentados no slam, ela se reflete também na lógica da realização do próprio evento: tanto nos critérios democráticos (Somers-Willett, 2009) que dizem respeito a quem pode ser o poeta, de que assunto ele pode falar, quem pode assistir, quem pode julgar uma poesia, com base em que princípios; quanto na lógica de ocupação que rege o espaço de realização do evento em si, o que evidencia ainda mais a natureza do Slam Resistência enquanto fórum.

O uso da lei contra a opressão da polícia por parte dos organizadores do Slam Resistência lembra a história contada por James Holston (2009) sobre a mudança observada por ele, no período entre os anos 1972 e 2003, na relação de moradores da periferia de São Paulo com a lei e a cidadania. Em 1972, no Jardim das Camélias, um oficial de justiça veio comunicar a irregularidade da posse de terra por parte dos moradores e ordenar seu despejo. A confusão se formou e o oficial foi atacado fisicamente por alguns moradores, o que resultou na prisão de diversas pessoas. Depois disso, políticos locais contrataram um advogado para resolver o caso e ajudar os moradores. $\mathrm{O}$ advogado foi assassinado ao deixar uma das casas da vizinhança. Trinta e um anos depois, em 2003, no Lar Nacional, bairro da periferia de São Paulo também estudado por Holston, um outro oficial do governo veio fazer o mesmo comunicado. Ele foi encaminhado à associação de moradores, que o recebeu com documentos que provavam legalmente que a Secretaria Municipal de Tesouro estava errada. Dessa vez, os moradores sabiam de seus direitos, entendiam do funcionamento do sistema judicial e instruíram o oficial a procurar a lei. O oficial foi embora, convencido de que a questão não tinha mérito, e os moradores não voltaram a ser perturbados por representantes do governo.

A partir de histórias como essa, exemplo do que ele chama de cidadania insurgente, James Holston $(2008$; 2009) aponta para a transição na relação dos moradores das periferias de São Paulo com a lei e a questão da cidadania. Ele analisa como, antes, a palavra "cidadão" tinha um conceito derrogatório, usado para indicar que alguém não pertencia a determinando grupo, evidente no ditado "aos amigos tudo, aos inimigos a lei". Dessa forma, antes, a lei era sempre vista como um instrumento de punição. A partir da observação de assentamentos sociais na periferia "autoconstruída" de São Paulo - construída pelos próprios trabalhadores, que ao mesmo tempo que construíam suas próprias casas, construíam, com o seu trabalho, a própria cidade de São Paulo -, Holston percebe que ao longo dos anos, os moradores dessa área passaram a usar a lei a seu favor, como instrumento de garantia de direitos.

Dessa maneira, para usarmos o vocabulário de Holston $(2008$; 2009), a performance de cidadania do Slam Resistência se caracterizaria como uma prática insurgente contra o regime de cidadania diferenciada construído historicamente pelas elites dentro da nação brasileira. Holston emprega o termo "cidadania diferenciada" para descrever regimes como o da cidadania brasileira, legalmente projetados para legitimar a distribuição das desigualdades dentro do sistema social. Contudo, para Holston, diferentemente do slam que ocupa a praça, as 
performances de cidadania insurgente geralmente ocorrem no nível da micropolítica, em pequenas ações da vida cotidiana das pessoas, que dificilmente aconteceriam no centro da pólis, mas sim, no espaço privado do oikos, se restringindo, na maioria das vezes, ao espaço da periferia da cidade. "É uma insurgência que começa com a luta pelo direito de ter uma vida diária na cidade digna de um cidadão", de modo que a demanda por essa nova cidadania surge em "termos de habitação, propriedade, esgoto, creche, segurança e outros aspectos da vida residencial" (Holston, 2009, p. 246, tradução nossa).

No Slam Resistência, o limite entre oikos e pólis é borrado, como podemos perceber a partir dos exemplos analisados neste texto. Assim como se afilia simultaneamente aos suportes oral, visual e escrito, o slam mistura as esferas do "público e privado, político e pessoal, estado e família, rua e casa, presença e ausência de lei, jurídico-institucional e biológico e assim por diante", domínios que Holston (2008, p. 312, tradução nossa) indica caberem, respectivamente, à pólis e ao oikos. O centro da cidade se torna palco de dramas que são, ao mesmo tempo, pessoais e coletivos. A prática da cidadania insurgente acontece, então, no centro da pólis, na ágora, no fórum, e toma a praça, quebrando a lógica de funcionamento da cidade neoliberal, reclamando o espaço da cidade enquanto espaço de festa e manifestação, como apontava Lefebvre (2008), apropriando, ocupando e ressignificando o espaço público. Em oposição aos enclaves fortificados, típicos da cidade de São Paulo pós-anos 1990, à autossegregação das elites e classes médias, que abriram mão de conviver com a diversidade que é necessariamente a cidade, o slam ocupa a praça.

Nos debates atuais sobre o direito à cidade - intrinsicamente ligado à questão da cidadania e da democracia - identificam-se dois fatores centrais que agem como limitadores do acesso a esse direito: a lógica da cidade neoliberal, que sufoca a urbanidade, divide e regulamenta o uso dos espaços, transformando valor de uso em valor de troca; e a violência, praticada também por civis, mas, principalmente, aquela perpetrada pelo Estado contra uma categoria específica de cidadãos.

A emergência de cidadãos dessa categoria ao lugar de novos atores culturais na cidade é uma das novidades mais significativas na história recente de São Paulo, aponta Raquel Rolnik (2017). A "ampliação das possibilidades de circulação e presença, especialmente dos jovens moradores das periferias mais distantes" e "a ruptura com a hegemonia do automóvel sobre todas as formas de circulação [...] em conjunto, vinha mudando a cara da capital paulista" (Rolnik, 2017, p. 190). Os grafites nos muros e as praças ocupadas com poesia são como inscrições desses atores na superfície da cidade, que revelam o quanto ela também pertence a eles. São escritas que a administração de Dória tenta apagar.

As noções de circulação e presença são centrais para aquilo que os praticantes dessa nova modalidade de cidadania enxergam como participação democrática. $\mathrm{O}$ consumo enquanto forma de participação social, como apontava Canclini (2010), não basta a esses jovens. Não à toa, as manifestações de junho de 2013 começaram por causa do valor da passagem de ônibus. Mas não era por vinte centavos, era por direitos, todos diziam. Era por uma vida sem catracas. Depois de algumas manifestações, todas essas causas se revelaram entrelaçadas.

"Em diálogo direto com a profundidade da história, tão perto e tão longe da política e da gestão", afirmam os/as organizadores/as da coletânea Junho: potência das ruas e das redes em sua introdução:

vemos junho como produto e gerador de um novo tempo de desejos e mundos políticos que se encontra nas ruas e nos gritos de um Brasil menor, radicalmente diferente de um Brasil potência. [...] Junho está sendo, junho é, junho será. Está vivo, dentro de nós, diluído nas novas subjetividades, flutuando sobre um novo ecossistema social, criando novos espaços de política lateral. Junho será, nas redes e nas ruas. Junho é. Vive nas micropolíticas, nos muitos projetosprocessos sonhados de forma coletiva: nas cidades, favelas, universidades, nos quilombos, nas florestas, nos corpos que procuram liberdade. Chegará de surpresa, como uma nova explosão emocional, como uma nova gramática social (Moraes et al., 2014, p. 530-535).

A vigência de junho se faz visível no Slam Resistência. Ao ocupar a praça (e a rede) e reclamar por direitos, seus poetas, organizadores e público adotam novas gramáticas - novas formas, significados e funções - para produzir a cidade, produzir poesia e produzir vida. 


\section{Referências}

CANCLINI, Nestor Garcia (2010). Consumidores e cidadãos: conflitos multiculturais da globalização. Tradução de Maurício Santana Dias e Javier Rapp. Rio de Janeiro: Editora UFRJ.

D'ALVA, Roberta Estrela (2011). Um microfone na mão e uma ideia na cabeça: o poetry slam entra em cena. Synergies Brésil, n. 9, p. 119-126. Disponível em: https://gerflint.fr/Base/Bresil9/estrela.pdf. Acesso em: 20 dez. 2019.

DAMON, Maria (1998). Was that "diferente", "dissidente" or "dissonante"? Poetry (n) the public spear: slams, open readings, and dissident traditions. In: BERNSTEIN, Charles (Ed.). Close listening: poetry and the performed word. Oxford: Oxford University Press, p. 324-342.

GREGORY, Helen (2008). (Re)Presenting ourselves: art, identity and status in U.K. poetry slam. Oral Tradition, v. 23, n. 2, p. 201-217. Disponível em: https://bit.ly/2tulgX4. Acesso em: 20 dez. 2019.

GREGORY, Helen (2012). Poetry performances on the page and stage: insights from slam. In: GINGEL, Susan; ROY, Wendy (Ed.). Listening up, writing down, looking beyond: interfaces of the oral, written, and visual. Waterloo: Wilfrid Laurier University Press.

HOLSTON, James (2008). Insurgent citizenships: disjunctions of democracy and modernity in Brazil. Princeton: Princeton University Press.

HOLSTON, James (2009). Insurgent citizenship in an era of global urban peripheries. City and Society, v. 21, n. 2, p. 245-267. Disponível em: https:// bit.ly/2SS53FR. Acesso em: 20 dez. 2019.

LEFEBVRE, Henri (2008). O direito à cidade. Tradução de Rubens Eduardo Frias. São Paulo: Centauro.

MORAES, Alana et al. (Org.) (2014). Junho: potência das ruas e das redes. São Paulo: Friedrich Erbert Stiftung.

PERRY, Irmani (2004). Prophets of the hood: politics and poetics in hip hop. Durham \& London: Duke University Press.

RACIONAIS MC's (2002). Negro drama. In: RACIONAIS MC's. Nada como um dia após o outro dia. São Paulo: Cosa Nostra. Disponível em: https://open.spotify.com/album/4HcPzKyKVtcZCwJgesoZWn. Acesso em: 20 dez. 2019.

ROLNIK, Raquel (2017). Territórios em conflito: São Paulo: espaço, história e política. São Paulo: Três Estrelas.

SLAM - Voz de Levante. Direção: Tatiana Lohmann e Roberta Estrela D'Alva. Globo Filmes. Documentário. $81 \mathrm{~min}$.

SLAM RESISTÊNCIA (2016a). Patricia Meira chegou esses dias no rolê e já tá arrasando e levando um monte de Slam! Slam Resistência - Novembro/2016. Fanpage Slam Resistência no Facebook, São Paulo, 16 nov. Vídeo. Disponível em: https://www.facebook.com/slamresistencia/videos/1170540129695371/. Acesso em: 28 fev. 2018.

SLAM RESISTÊNCIA (2016b). Lucas Penteado Kóka, símbolo das ocupações de secundaristas em SP e o grande vencedor do Slam Resistência - edição de dezembro/2016. Fanpage Slam Resistência no Facebook, São Paulo, 12 dez. Disponível em: https://www.facebook.com/slamresistencia/videos/1204045536344830/. Acesso em: 28 fev. 2018.

SLAM RESISTÊNCIA (2016c). Daniel Gtr (Daniel Carvalho) mais uma vez mexendo na ferida da bancada da bala evangélica. Fanpage Slam Resistência no Facebook, São Paulo, 22 dez. Vídeo. Disponível em: https://www.facebook.com/slamresistencia/videos/1215372628545454/. Acesso em: 28 fev. 2018.

SLAM RESISTÊNCIA (2016d). Lucas Afonso, representante do Brasil na França no ano passado, e neste ano, foi finalista do nosso Slam. Fanpage Slam Resistência no Facebook, São Paulo, 21 dez. Vídeo. Disponível em: https://www.facebook.com/slamresistencia/videos/1212769128805804/. Acesso em: 28 fev. 2018.

SLAM RESISTÊNCIA (2017a). Confiram a poesia autobiográfica de Paulina Turra!. Fanpage Slam Resistência no Facebook, São Paulo, 7 ago. Vídeo. Disponível em: https://www.facebook.com/slamresistencia/videos/1442074925875222/. Acesso em: 28 fev. 2018.

SLAM RESISTÊNCIA (2017b). O feminismo não deveria existir!. Fanpage Slam Resistência no Facebook, São Paulo, 22 mar. Vídeo. Disponível em: https://www.facebook.com/slamresistencia/videos/1309029562513093/. Acesso em: 28 fev. 2018. 
SLAM RESISTÊNCIA (2017c). Slam Resistência - primeira edição de 2017. Fanpage Slam Resistência no Facebook, São Paulo, 7 mar. Vídeo. Disponível em: http://www.facebook.com/slamresistencia/videos/1293755650707151/. Acesso em: 28 fev. 2018.

SOMERS-WILLET, Susan B. A. (2001). Slam Poetry: ambivalence, gender and authenticity in "slam". Text, Practice and Performance, Texas, v. 3, p. 37-63. Disponível em: https:/ / bit.ly/2SVgHzB. Acesso em: 20 dez. 2019.

SOMERS-WILLET, Susan B. A. (2009). The cultural politics of slam poetry: race, identity and the performance of popular verse in America. Ann Arbor: University of Michigan Press.

SPIVAK, Gayatri Chakravorty (1987). Subaltern studies: deconstructing historiography. In: SPIVAK, Gayatri Chakravorty. Other worlds: essays in cultural politics. Nova York; Londres: Routledge. p. 197-221.

TEPERMAN, Ricardo (2011). Tem que ter suíngue: batalhas de freestyle no metrô Santa Cruz. Dissertação (Mestrado em Antropologia Social) - Universidade de São Paulo, São Paulo.

ZUMTHOR, Paul (2014). Performance, recepção e leitura. Tradução de Jerusa Pires Ferreira e Suely Fenerich. São Paulo: Cosac Naify.

\section{Nota}

Este artigo é decorrente da tese de doutorado intitulada Ensaios sobre o rap e o slam na São Paulo contemporânea, defendida pela autora em abril de 2018 na Pontifícia Universidade Católica do Rio de Janeiro (PUC-Rio). 